\title{
Perinatal COVID-19: a case report, literature review, and proposal of a national system for case record
}

\author{
Victoria Lima-Rogel', Raúl Villegas-Silva², Alejandra Coronado-Zarco ${ }^{3}$, Isaac Estrada-Ruelas ${ }^{4,5}$, \\ Alma R. Sánchez-De la Vega ${ }^{6,7}$, Raúl H. Muro-Flores ${ }^{8,9}$, and Mónica Villa-Guillén ${ }^{10 *}$ \\ ${ }^{1}$ Hospital General Ignacio Morones Prieto, San Luis Potosí, San Luis Potosi; ' ${ }^{2}$ Departamento de Neonatología, Hospital Infantil de México Federico \\ Gómez, Mexico City; ${ }^{3}$ Departamento de Neonatología, Instituto Nacional de Perinatología Isidro Espinosa de los Reyes, Mexico City, Mexico; \\ ${ }^{4}$ Federación Nacional de Neonatología de México, Mexico City; ${ }^{5}$ Coordinación Clínica de Neonatología, Hospital de Gineco-Obstetricia, Unidad de \\ Medicina Familiar No. 7, Instituto Mexicano del Seguro Social, Tijuana, Baja California; ${ }^{6}$ Unidad de Cuidados Intensivos Neonatales, Hospital General \\ Dr. Carlos Canseco, Tampico, Tamaulipas; ${ }^{7}$ Departamento de Pediatría, Hospital de Beneficencia Española, Tampico, Tamaulipas; ${ }^{8}$ Unidad de Cuidados \\ Intensivos Neonatales, Hospital General de Zona No. 46 Dr. Bartolomé Reynés Berezaluce, Instituto Mexicano del Seguro Social, Villahermosa, \\ Tabasco; ${ }^{9}$ Asociación de Neonatólogos de Tabasco, Tabasco; ${ }^{10}$ Dirección Médica, Hospital Infantil de México Federico Gómez, Mexico City. Mexico
}

\begin{abstract}
Background: On March 11, 2020, the World Health Organization declared the severe acute respiratory syndrome coronavirus-2 (SARS-CoV-2) pandemic, and on February 28, Mexico reported its first case. Internationally, cases in newborns are few and the outcomes, in general, are good. There is no certainty of possible vertical transmission, and the presence of the virus in human milk is improbable. The gold standard for diagnosis is the reverse transcription-polymerase chain reaction (RT-PCR) test. We performed a literature review and presented a case of perinatal COVID-19. Clinical case: We describe the case of a full-term male infant with a birth weight of $3450 \mathrm{~g}$ and history of rooming-in with another mother-baby pair, both positive for SARS-CoV-2. On the second day of life, the neonate developed pneumonia, with clinical, X-ray and ultrasound diagnostic confirmation. On the third day of life, RT-PCR was positive for SARS-CoV-2; the mother was also positive but remained asymptomatic. The patient required mechanical ventilation and was transferred to a tertiary level neonatal unit on day 5 of life, where congenital heart disease was ruled out. He evolved satisfactorily with a negative RT-PCR test for SARS-CoV-2 on day 8 and was extubated and discharged on day 21 of life. Telephone follow-up was performed without complications. Conclusions: The present case was classified as horizontal transmission with a short incubation period of COVID-19.
\end{abstract}

Key words: COVID-19. Severe acute respiratory syndrome coronavirus-2. Newborn. Case report. Literature review. Horizontal transmission. Database.

\section{COVID-19 perinatal: reporte de caso, revisión de la literatura y propuesta de un sistema nacional de registro de casos}

\section{Resumen}

Introducción: El 11 de marzo de 2020 la Organización Mundial de la Salud declaró la pandemia por SARS-CoV-2 y el 28 de febrero México reportó su primer caso. En todo el mundo, los casos en recién nacidos son pocos y la evolución, en general, es buena. No hay certeza sobre la posible transmisión vertical, y la presencia del virus en la leche humana es

\section{Correspondence:}

*Mónica Villa-Guillén

E-mail: monicavillag@yahoo.com;

mvillaguillen@himfg.edu.mx

Date of reception: 27-07-2020

Date of acceptance: 14-08-2020

DOI: 10.24875/BMHIM.20000230
Available online: 24-02-2021

Bol Med Hosp Infant Mex. 2021;78(1):34-40 www.bmhim.com 1665-1146/@ 2020 Hospital Infantil de México Federico Gómez. Published by Permanyer. This is an open access article under the CC BY-NC-ND license (http://creativecommons.org/licenses/by-nc-nd/4.0/). 
altamente improbable. El método de referencia para el diagnóstico es la prueba de reacción en cadena de la polimerasa con transcriptasa inversa (RT-PCR). Se presenta un caso clínico de COVID-19 perinatal y se llevó a cabo una revisión de la literatura sobre el tema. Caso clínico: Recién nacido de sexo masculino, de término, con un peso al nacer de 3,450 g, con antecedente de alojamiento conjunto con otro binomio madre-hijo positivo para SARS-CoV-2. Al segundo día de vida desarrolló neumonía diagnosticada por clínica, rayos X y ultrasonido. Presentó prueba positiva para SARS-CoV-2 al día 3 de vida, al igual que la madre, quien permaneció asintomática. El paciente requirió ventilación mecánica y fue trasladado a una unidad neonatal de tercer nivel el día 5 de vida, donde se descartó cardiopatía congénita y evolucionó satisfactoriamente. La prueba de RT-PCR para SARS-CoV-2 fue negativa al día 8, por lo que se realizó extubación y egreso al día 21 de vida. Se realizó seguimiento telefónico, sin complicaciones. Conclusiones: El presente caso fue catalogado como transmisión horizontal con un periodo corto de incubación de COVID-19.

Palabras clave: COVID-19. SARS-CoV-2. Neonato. Reporte de caso. Revisión de la literatura. Transmisión horizontal. Base de datos.

\section{Introduction}

On February 28, Mexico reported the first case of severe acute respiratory syndrome coronavirus-2 (SARS-CoV-2) infection, which was acquired in Italy, transferred from Wuhan through Germany and Italy, according to the phylogenetic study conducted by Foster et al. ${ }^{1}$ This virus spread across all continents, and the World Health Organization declared a global emergency on January 30, 2020. On March 11, the World Health Organization declared a pandemic (which to date, May 15 , has affected $4,474,757$ people, with a fatality rate of $\left.6.8 \%{ }^{2,3}\right)$. The basal reproduction number (R0) for this virus is 2-3. However, damage correction mechanisms to its genome (proofreading) and recombination with other coronaviruses allows SARS-CoV-2 to increase its virulence ${ }^{4}$. Furthermore, factors such as a short incubation period, the mode of transmission (airborne droplets), the time it remains in the air and on surfaces, the global population density, days the virus remains in people, whether in confirmed, symptomatic negative, or asymptomatic positive cases have permitted its spread on a large scale . $^{5}$

\section{Diagnosis}

According to the report of 2143 pediatric COVID-19 cases in China $^{6}$, and the report of 2572 cases (1.7\% of the population) by the U.S. Centers for Disease Control and Prevention ${ }^{7}$, clinical manifestations in children with COVID-19 included fever, fatigue, myalgia, cough, odynophagia, rhinorrhea, sneezing, nausea, vomiting, abdominal pain, diarrhea, and in severe cases, a progression over 7 days to manifestations of hypoxia such as dyspnea, central cyanosis, and oxygen saturation $<92 \%$.

The severe form is similar to adult-type respiratory distress syndrome (RDS) or hypoxemic respiratory failure and can occur with shock, encephalopathy, myocardial injury or heart failure, intravascular coagulation, and acute kidney damage with organ dysfunction.

In the study conducted by Dong et al., most pediatric cases were mild: only one patient died and $5.9 \%$ cases were severe or critical ${ }^{6}$.

Other clinical findings that have been described include skin lesions, toxic shock, conjunctivitis, and multi-inflammatory systemic syndrome, a condition similar to Kawasaki disease ${ }^{8,9}$.

In neonates, a vertical transmission has not been confirmed to date. Four possible cases have been reported. The first is an anecdotal report in a local newspaper (Guardian and Sun) in London, in a newborn during the first hour of life. The second case was reported recently in Peru, the child of a mother with severe COVID-19 and positive for SARS-CoV-2 at $16 \mathrm{~h}$ of birth ${ }^{10}$. Kirtsman et al. ${ }^{11}$ reported the case of a 40-year-old mother with family neutropenia and severe COVID-19, whose 35-week-old newborn, born by cesarean section, was positive for SARS-CoV-2 detected by reverse transcriptase-polymerase chain reaction (RT-PCR) at birth, at 2 and 7 days of age. This newborn presented neutropenia, mild hypothermia, feeding difficulty, and intermittent hypoglycemia episodes that required intensive care. The placental analysis revealed multiple inflammatory infiltration areas compatible with chronic histiocytic intervillositis, for which it was considered a case of probable congenital COVID-19.

In China, at the beginning of the outbreak, a daughter of a patient with severe COVID-19 was reported to have immunoglobulin M (IgM) in her blood $2 \mathrm{~h}$ after birth ${ }^{12}$, although the RT-PCR test for SARS-CoV-2 was negative in the amniotic fluid and human milk. Cases with respiratory symptoms and negative RT-PCR have been reported in several series of newborns of mothers with COVID-19 ${ }^{12-19}$. To date, not every serological diagnostic 
test for SARS-CoV-2 infection has been reliable enough. In a systematic review and meta-analysis that included 40 studies and 29,842 tests, the most sensitive was the chemiluminescence immunoassay $(97.8 \%$ of sensitivity), and the least sensitive was the lateral flow immunoassay (LFIA) $(66 \%$ of sensitivity). The sensitivity increases when testing is performed $\geq 3$ weeks after the onset of symptoms ${ }^{20}$. Regarding human milk, some studies have detected the virus presence in it ${ }^{21}$. In contrast, a systematic review that included eight newborns and 24 pregnant women with COVID-19 during the third trimester of pregnancy (all with symptoms of acute respiratory illness and chest computed tomography images indicating COVID-19 pneumonia) reported negative results in pharyngeal or nasopharyngeal samples from newborns and placentas, and no breast milk samples were positive for SARS-CoV-222. Regarding these initial reports, Kimberlin and Stagno pointed out that there is no evidence of vertical transmission to date, but the possibility exists since the virus is in the blood ${ }^{23}$.

Wang et al. also analyzed the possibility of vertical transmission and suggested a follow-up of newborns with elevated $\lg G$ and $\operatorname{lgM}$ at birth, whose mothers were positive, since vertical transmission may be suspected if positivity persists. Furthermore, these authors consider that if the placentas and fetuses of early losses are analyzed, the virus exposure in the intrauterine stage could be confirmed ${ }^{24}$.

In a systematic review by Yang and Liu, 22 studies and 83 infants born to mothers with SARS-CoV-2 positive RT-PCR were analyzed. Three neonates tested positive at 16,36 , and $72 \mathrm{~h}$ of life, and specific antibodies were found in six neonates after birth. However, the virus presence was not confirmed in amniotic fluid, placenta, or umbilical cord in any case, so there is no virological evidence of vertical intrauterine transmission to date ${ }^{25}$. Given all these findings and the possibility of mutation -ten mutations in its path from the bat to Wuhan, Germany, Italy, and finally Mexico ${ }^{1}$-we must be alert and aware. Other examples of viruses, such as Zika, acquired neurotropic properties when it arrived in Brazil ${ }^{26}$. The SARS-CoV-2 virus might acquire mutations in its genome that would allow its vertical transmission.

\section{Clinical picture in neonates born to mothers with COVID-19 at birth with negative RT-PCR test}

Neonates born to mothers with COVID-19 have prematurity-related morbidities such as intrauterine growth restriction. Congenital malformations associated with
COVID-19 have not been documented in the literature yet; it is likely in very early infection cases but has not been described.

Clinical features of infected newborns, especially premature ones, might be nonspecific and include acute RDS, temperature instability, and gastrointestinal and cardiovascular dysfunction ${ }^{27}$. In different case reports, most newborns evolve favorably without complications or with mild manifestations. Zhu et al. reported that some newborns presented tachycardia, tachypnea, respiratory distress, fever, vomiting, oral feeding rejection, as well as thrombocytopenia, and altered hepatic tests $^{19}$. The chest X-ray showed pneumonia in four patients, RDS in two, and pneumothorax in one. One patient died of refractory shock, intravascular coagulation, and multiple organ failure, although the neonate tested negative for SARS-CoV-2.

In a report published by Yang et al., two neonates presented moderate RDS and required nasal continuous positive airway pressure (CPAP) exclusively ${ }^{28}$.

\section{Horizontal transmission of COVID-19 in the neonatal period after birth}

At the start of the pandemic, two patients were reported positive at $36 \mathrm{~h}$ and 17 days after birth; the contacts were the mother and a caregiver ${ }^{16,29}$. Coronado et al. ${ }^{30}$ reported a 3-week-old patient with a 2-day evolution of nasal congestion, tachypnea, and decreased milk intake. On admission, the patient presented an oxygen saturation of $87 \%$. Chest X-ray showed right apical pneumonia and bilateral infiltrates; also, the patient presented hypotension, tachycardia, hypothermia, and tachycardia. The patient required intubation and ventilatory assistance and presented pneumothorax as a complication. The RT-PCR test for SARS-CoV-2 was positive 7 days after admission. Contact with a 49-year-old relative with respiratory symptoms was reported.

Zeng et al. ${ }^{27}$ reported a series of 33 newborns of mothers with COVID-19: three of them were symptomatic (one premature with a gestational age of 31 weeks), with radiological evidence of pneumonia. The nasopharyngeal and rectal tests were positive for SARS-CoV-2. These newborns showed a worse clinical course than the others reported to date. However, the outcomes were good, with a negative test 6 days after the onset of symptoms in two newborns and 7 days in the third one. The newborn born at 31 weeks of gestation developed coagulopathy associated with Enterobacter infection, which resolved with recovery from sepsis. None 
of the newborns died. The contact was the mother in two cases and the father in one.

Alonso et al. reported the case of a newborn with a mother positive for COVID-19 in Spain, who presented mild respiratory distress at birth and required ventilatory assistance with nasal CPAP. After $2 \mathrm{~h}$, breathing was normal, and the newborn was diagnosed with transient tachypnea. Two days later, the mother, whose partner had had fever days earlier, also developed fever and gastroenteritis; the test for SARS-CoV2 was positive for both. On the sixth day of life, the newborn was tested negative for SARS-CoV-2 by RT-PCR, but on day 9 of life, the newborn started with intercostal retractions and low oxygen saturation. The chest $X$-ray showed a subtle ground-glass image and was positive for SARS-CoV-2. At $24 \mathrm{~h}$, symptoms resolved, although the newborn continued to test positive in the SARS-CoV-2 RT-PCR even at day 13 of life ${ }^{31}$.

The patient reported by Alzamora et al. was the product of a mother with diabetes mellitus and severe respiratory distress. The newborn presented positive RT-PCR for SARS-CoV-2 at $16 \mathrm{~h}$ of birth. The patient was intubated due to maternal sedation and extubated successfully. After 6 days, the newborn presented a cough and mild respiratory distress that required the administration of supplemental oxygen by nasal cannula. Laboratory tests and chest $\mathrm{X}$-ray results were normal ${ }^{10}$.

The most recent report is on a newborn of 26 weeks of gestation, son of a mother with preeclampsia and HELLP syndrome (hemolysis, increase of liver enzymes, thrombocytopenia) who was born by cesarean section with a weight of $960 \mathrm{~g}$ and Apgar of 5, 8, and 8 at 1 , 5 , and $10 \mathrm{~min}$, respectively. The patient showed RDS, pneumothorax, and patent ductus arteriosus with hemodynamic repercussions, which resolved favorably. One day after the $\mathrm{C}$-section, the mother presented fever and cough with a C-reactive protein of $85 \mathrm{mg} / \mathrm{L}$ and $214 \mathrm{mg} / \mathrm{L} 24 \mathrm{~h}$ later. Antibiotics were administered for suspected urinary tract infection. On day 6 , the mother developed respiratory distress and pneumonia and was positive for SARS-CoV-2 by RT-PCR test. On day 7, the newborn was also positive for SARS-CoV-2, with lymphopenia as the only manifestation ${ }^{32}$.

\section{Diagnostic tests}

At present, the gold standard for the diagnosis of SARS-CoV-2 infection is the nucleic acid amplification test by RT-PCR. This test can detect the virus during the peak of the disease and during its contagious period, which is of variable duration. The sensitivity of the test is $71 \%$ when compared to lung tomography ${ }^{33}$.
If a viral culture of the nasopharyngeal sample is performed (not recommended because of the biological risk), it is usually positive in the first 7-8 days of the disease. Sensitivity may be higher in tracheal aspiration samples; however, the risk of aerosol contamination is high, even with closed-loop sampling.

As for serology tests, although $\lg G$ and $\lg M$ antibodies can be positive as early as the fourth day after symptoms, the highest levels occur in the second or third week of the disease. IgM decreases at 5 weeks and disappears at 7 weeks, and IgG persists $>7$ week $^{34}$. The chemiluminescent immunoassay test has a sensitivity of $97.8 \%$, the enzyme-linked immunoassay has a sensitivity of $84.3 \%$, and the LFIA has a sensitivity of $66 \%$; rapid testing is not recommended ${ }^{21}$.

The determination of RT-PCR in feces has a positivity of $57 \%$ and persists positive $4-11$ days on average ${ }^{35}$.

\section{Clinical case}

We describe the case of a 5-day-old male patient from a referral hospital, son of a 19-year-old mother with type I diabetes mellitus (diagnosed at age 13 and managed with insulin). The patient was born by cesarean section since fetal bradycardia was detected during labor. The mother was asymptomatic and was hospitalized for post-operative monitoring in the low-risk postpartum ward in a room shared with another woman in postpartum, whose child was born on the same date. The other woman presented fever and pharyngeal pain on the second day of postpartum. As COVID-19 was suspected, an RT-PCR for SARS-CoV-2 was performed on both women and the two newborns: all were positive. The mother and her son sharing the room were released for outpatient monitoring 2 days later. The father spent the first few days with the mother and child during the family visit before the molecular diagnosis, so he was tested 1 day after the mother's diagnosis and was also positive for SARS-CoV-2.

The described patient was born with a birth weight of $3450 \mathrm{~g}$ at 40 weeks of gestation and Apgar of 9-9. As no reanimation maneuvers were required, the newborn was initially hospitalized in a room with the mother. The patient presented polypnea and low oxygen saturation on the second day of life, so supplementary oxygen was initiated. On the third day of life, CPAP was added. On the fourth day, it was decided to start invasive ventilation, and the patient was transferred to the neonatal intensive care unit (NICU). In the delivery unit, coarctation of the aorta with hypoplasia of the aortic arch was suspected by echocardiography. 
The patient was received with endotracheal intubation in a closed incubator, with adequate transport, presenting discrete polypnea and intercostal retractions, without rales, with the following ventilatory parameters: intermittent positive pressure $=18 \mathrm{~mm} \mathrm{H}_{2} \mathrm{O}$, positive end-expiratory pressure $=6 \mathrm{~mm} \mathrm{H}_{2} \mathrm{O}, 40$ cycles/min, and a fraction of inspired oxygen $\left(\mathrm{FiO}_{2}\right)$ of $40 \%$. The patient remained stable in good condition for 3 days, with no added treatment other than sedation-analgesia with morphine. Ductus arteriosus in remission with mild pulmonary hypertension was identified, and coarctation of the aorta was discarded. Subpleural consolidations, mild interstitial pattern infiltrates, and air bronchogram were observed on the lung ultrasound. The chest X-ray showed multiple infiltrates as well as major cardiomegaly. As aggregates, vertebral alterations were identified with two hemivertebrae and discrete scoliosis (Fig. 1). Blood biometry, blood chemistry, creatine phosphokinase (CPK), coagulation tests, and troponin were normal.

On the fifth day, we decided to extubate the patient and place nasal CPAP $6 \mathrm{cmH}_{2} \mathrm{O}$ and $\mathrm{FiO}_{2}=30 \%$. The patient showed a good evolution, and 10 days later, he still required oxygen through low-flow nasal tips, without respiratory difficulty. Control X-rays and ultrasound of the lung showed clear progressive improvement and a decreased cardiac size. A subsequent lung control ultrasound was normal. No antimicrobials or antiviral therapy were used. RT-PCR for SARS-CoV-2 at 8 days of age was negative.

Three days before discharge, the oxygen supply was withdrawn. The patient was discharged at 21 days of age in good general conditions. Weekly telephonic follow-up was made for a month. The parents reported that the newborn was in excellent condition and with normal activity.

\section{Discussion}

We consider the present case similar to the one described by the Spanish group of Alonso et al. ${ }^{31}$ since both patients were sons of a diabetic mother and developed early respiratory distress with increasing needs for ventilatory support to the point of intubation. The COVID-19 infection was demonstrated without having been suspected in the asymptomatic mother. Disseminated but not severe pulmonary involvement was also found. This circumstance allowed the problem to be resolved without any experimental treatment. The resolution was demonstrated by clinical, radiological,

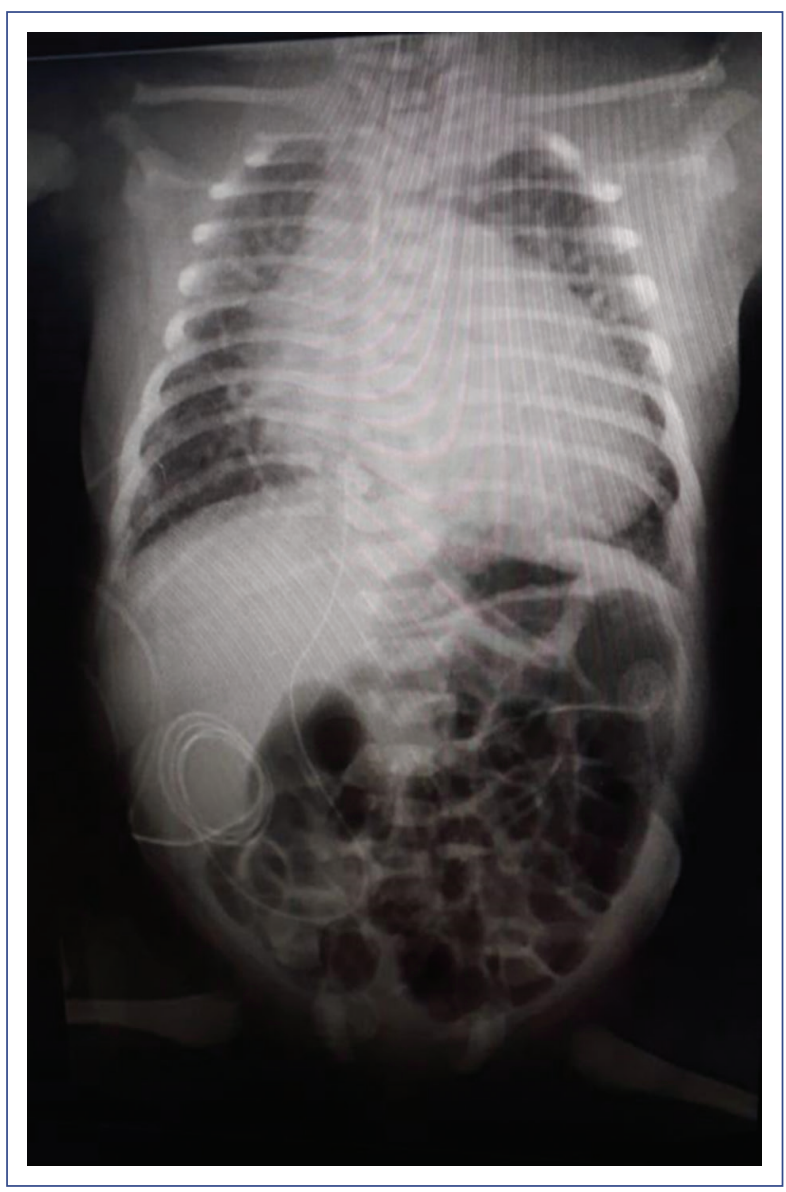

Figure 1. Chest $X$-ray showing multiple infiltrates, as well as cardiomegaly and vertebral alterations with two hemivertebrae and discrete scoliosis.

and ultrasound imaging, as well as RT-PCR testing with negative results.

Clinical manifestations in the newborn are predominantly pulmonary. In this regard, the present case is similar to the publication of Zeng et al. ${ }^{27}$, who reported three newborns, two full-term and one premature of 31 weeks of gestation with pneumonia and positive for SARS-CoV-2 at 2 and 4 days of life, and negative at 6-7 days. The preterm infant also had RDS, perinatal asphyxia, sepsis, and coagulopathy and required mechanical ventilation. Clinical manifestations were lethargy and fever in one case, lethargy, vomiting, and fever in another, and data on perinatal asphyxia and RDS in the preterm infant. The present case presented with polypnea and oxygen desaturation. As for laboratory tests, one full-term newborn presented elevated procalcitonin, while the other full-term newborn had leukocytosis, lymphopenia, and increased creatine kinase MB (CPK-MB). Leukocytosis, thrombocytopenia, 
and extended coagulation times were present in the preterm infant, which could be explained by the comorbidities associated with prematurity. In the present case, there were no laboratory alterations.

Since clinical manifestations were present on the second day of life, the question regarding the moment of transmission remains. An average incubation period of 5-7 days has been described; therefore, it could be a case of vertical transmission. However, no strict postbirth isolation techniques were performed. In addition, a history of cohabitation with another mother, her newborn, and the symptomatic father, and the fact that everyone in the room was positive for SARS-CoV-2 should be considered. This situation explains why we are most likely looking at a case of horizontal transmission with a short incubation period. In Belgium, Piersigilli et al. ${ }^{32}$ reported the case of a 26-week-old newborn who acquired the postnatal infection probably from his mother, with whom he had only one contact on day 6 of life. One day later, the newborn showed data of infection and was positive for SARS-CoV-2. This case demonstrates a horizontal transmission. However, it is always important to consider all potential routes, including vertical or congenital transmission and perinatal or postnatal transmission through aerosols, droplets, or direct contact.

Even in a controlled NICU, the great easiness of transmission of this virus should be emphasized. Therefore, it is of utmost importance to establish national and local guidelines not only for the handling of aerosols, droplets, and contact precautions but also for all family members and personnel entering the unit to prevent horizontal or nosocomial transmission of the virus. A questionnaire should be applied, including fever and respiratory symptoms. It is also important to test all suspected cases and their contacts and establish exclusive areas for suspected and confirmed COVID-19 patients, in which personal protective equipment must be used rigorously. Evidently, healthcare staff should be trained in how to wear it and remove it.

In the case described, vertebral malformations are more related to maternal type I diabetes mellitus than infection since birth weight was adequate. No histological evidence of the placenta was considered because it is not routinely studied in all births.

As described in the different case series, the evolution in the newborn is good, with complete resolution. It will be necessary to follow-up the patient in the future and evaluate pulmonary and neurological status.

This case also demonstrates that extreme care must be exercised in the care of all children at birth at this point in the pandemic since the maternal condition in most unplanned births is unknown, and ventilatory support may be needed in $1-3 \%$ of births, which were considered normal. Postpartum care in public hospitals can hardly be carried out in isolated places in all births. However, it must be considered that newborns with suspected or confirmed COVID-19 should be isolated and controlled, whether they are symptomatic or not, evaluating the need to create separate spaces for nurseries or NICUs to avoid transmission to other hospitalized newborns.

The medical visit should be arranged with all NICU healthcare personnel, as there will always be the possibility that parents who come to the visit will still be positive. Feeding through human milk should be attempted. However, healthcare team members' coordination is necessary to administer extracted human milk or milk directly from the mother's breast with strict hygiene and drop/contact protection measures.

Considering that a large percentage of the infected population may be asymptomatic and that pregnant women are susceptible to this type of infection, specific SARS-CoV-2 testing could be considered as part of pre-operative studies for pregnant women at the end of their pregnancy to reduce the risk of presenting manifestations of the infection at the time of the termination of the pregnancy in both the mother and the newborn. Similarly, testing of suspected mothers could reduce the risk of horizontal transmission. In particular, if the mother's results are negative, spaces limited to suspected newborns can be optimized. In referral hospitals, it is desirable to perform RT-PCR testing on any newborn requiring hospitalization. Obstetricians, neonatologists, and specialists in infectious diseases, as well as nurses, and all healthcare personnel in general, should focus on improving and using preventive methods in all areas of care in the most appropriate way.

\section{National System for Case Reports}

In Mexico, a National System for Case Reports was designed to collect the largest number of newborn patients with suspected or confirmed SARS-CoV-2 infection. The database will be available through the Federación Nacional de Neonatología de México (National Federation of Neonatology of Mexico) (http:// fnn.mx) and will be an open database, accessible to all neonatologists in the country. This information will allow us to know better the population concerning incidence, clinical presentation, and mortality, among other data, and to develop evidence-based management guidelines in the future. 


\section{Ethical disclosures}

Protection of human and animal subjects. The authors declare that no experiments were performed on humans or animals for this study.

Confidentiality of data. The authors declare that they have followed the protocols of their work center on patient data publication.

Right to privacy and informed consent. The authors have obtained the written informed consent of the patients or subjects mentioned in the article. The corresponding author has this document.

\section{Conflicts of interest}

The authors declare no conflicts of interest.

\section{Funding}

No funding was received.

\section{References}

1. Foster $P$, Foster $L$, Renfrew $C$, Foster M. Phylogenetic network analysis of SARS-CoV-2 genomes. Proc Natl Acad Sci USA. 2020;117:9241-3.

2. World Health Organization. Clinical Management of Severe Acute Respiratory Infection When Novel Coronavirus (nCoV) Infection is Suspected. Geneva: World Health Organization; 2020. Available from: https://www. apps.who.int/iris/bitstream/handle/10665/332299/who-2019-ncov-clinical2020.1-eng. .pdf? sequence $=1$ \&isallowed $=y$.

3. European Centre for Disease Prevention and Control. Update: Cluster of Pneumonia Cases Caused by a Novel Coronavirus, Wuhan, China, 2019. Solna: European Centre for Disease Prevention and Control; 2020. Available from: https://www.ecdc.europa.eu/en/news-events/update-cluster-pneumonia-cases-associated-novel-coronavirus-wuhan-china-2019.

4. Morens DM, Daszak P, Taubenberger JK. Escaping Pandora's box-another novel coronavirus. N Engl J Med. 2020;382:1293-5.

5. Cyranoski D. Profile of a killer virus. Nature. 2020;581:22-6.

6. Dong Y, Mo X, Hu Y, Qi X, Jiang F, Jiang Z, et al. Epidemiological characteristics of 2143 pediatric patients with 2019 Coronavirus disease in China. J Emerg Med. 2020;58:712-3.

7. CDC COVID-19 Response Team. coronavirus disease 2019 in children-United States, February 12-April 2, 2020. MMWR Morb Mortal Wkly Rep. 2020;69:422-6.

8. Jones VG, Mills M, Suarez D, Hogan CA, Yeh DJ, Segal B, et al. COVID-19 and Kawasaki disease: novel virus and novel case. Hosp Pediatr. 2020;10:537-40.

9. Cruz A, Zeichner S. COVID-19 in children: initial characterization of the pediatric disease. Pediatrics. 2020;145:e20200834.

10. Alzamora MC, Paredes T, Caceres D, Webb CM, Valdez LM, La Rosa M Severe COVID-19 during pregnancy and possible vertical transmission. Am J Perinatol. 2020;37:861-5.

11. Kirtsman M, Diambomba Y, Poutanen S, Malinowski AK, Vlachodimitropoulou E, Parks WT, et al. Probable congenital SARS-CoV-2 infection in a neonate born to a woman with active SARS-CoV-2 infection. CMAJ. 2020;192:E647-50.
12. Dong L, Tian J, He S, Zhu C, Wang J, Liu C, et al. Possible vertical transmission of SARS-CoV-2 from an infected mother to her newborn. JAMA. 2020;323:1846-8.

13. Chen $Y$, Peng $H$, Wang $L$, Zhao $Y$, Zeng $L$, Gao H, et al. Infants born to mothers with a new coronavirus (COVID-19). Front Pediatr. 2020;8:104.

14. Li A, Ng P. Severe acute respiratory syndrome (SARS) in neonates and children. Arch Dis Child Fetal Neonatal Ed. 2005;90:F461-5.

15. Chen H, Guo J, Wang C, Luo F, Yu X, Zhang W, et al. Clinical characteristics and intrauterine vertical transmission potential of COVID-19 infection in nine pregnant women: a retrospective review of medical records. Lancet. 2020;395:809-15.

16. Schwartz DA. An analysis of 38 pregnant women with COVID-19, their newborn infants, and maternal-fetal transmission of SARS-CoV-2: maternal coronavirus infections and pregnancy outcomes. Arch Pathol Lab Med. 2020;144:799-805. doi: 10.5858/arpa.2020-0901-SA.

17. Schwartz DA, Graham AL. Potential maternal and infant outcomes from Coronavirus 2019-nCoV (SARS-CoV-2) infecting pregnant women: lessons from SARS, MERS, and other human coronavirus infections. Viruses. 2020;12:194

18. Liu W, Wang Q, Zhang Q, Chen L, Chen J, Zhang B, et al. Coronavirus disease 2019 (COVID-19) during pregnancy: a case series. Preprints. 2020;2020020373. This version is not peer-reviewed.

19. Zhu H, Wang L, Fang C, Peng S, Zhang L, Chang G, et al. Clinical analysis of 10 neonates born to mothers with 2019-nCoV pneumonia. Transl Pediatr. 2020;9:51-60.

20. Bastos ML, Tavaziva G, Abidi SK, Campbell JR, Haraoui LP, Johnston JC, et al. Diagnostic accuracy of serological tests for COVID-19: systematic review and meta-analysis. BMJ. 2020;370:m2516.

21. Grob R, Conselmann C, Müller JA, Stenger S, Steinhart K, Kirchoff F, et al. Detection of SARS-CoV-2 in human breastmilk. Lancet. 2020;395: 1757-8.

22. Martins-Filho PR, Santos VS, Santos HP. To breastfeed or not to breastfeed? Lack of evidence on the presence of SARS-CoV-2 in breastmilk of pregnant women with COVID-19. Rev Panam Salud Publica. 2020;44:e59.

23. Kimberlin DW, Stagno S. Can SARS-CoV-2 infection be acquired in utero? More definitive evidence is needed. JAMA. 2020;323:1788-9.

24. Wang $\mathrm{C}$, Zhou YH, Yang HX, Poon LC. Intrauterine vertical transmission of SARS-CoV-2: what we know so far. Ultrasound Obstet Gynecol. 2020;55:724-5.

25. Yang Z, Liu Y. Vertical transmission of severe acute respiratory syndrome coronavirus 2: a systematic review. Am J Perinatol. 2020;37:1055-60.

26. Malone RW, Homan J, Callahan MV, Glasspool-Malone J, Damodaran L, Schneider AD, et al. Zika virus: medical countermeasure development challenges. PLoS Negl Trop Dis. 2016;10:e0004530.

27. Zeng L, Xia S, Yuan W, Yan K, Xiao F, Shao J, et al. Neonatal early-onset infection with SARS-CoV-2 in 33 neonates born to mothers with COVID-19 in Wuhan, China. JAMA Pediatr. 2020;174:722-5.

28. Yang $P$, Wang $X$, Liu $P$, Wei $C$, He B, Zheng J, et al. Clinical characteristics and risk assessment of newborns born to mothers with COVID-19. J Clin Virol. 2020:127:104356.

29. Qiao J. What are the risks of COVID-19 infection in pregnant women? Lancet. 2020;395:P760-2.

30. Coronado MA, Nawaratne U, McMann D, Ellsworth M, Meliones J, Boukas K. Late onset neonatal sepsis in a patient with COVID-19. N Engl J Med. 2020;382:e49.

31. Alonso DC, López MM, Moral PM, Flores AB, Pallás AC. Primer caso de infección neonatal por SARS-CoV-2 en España. An Pediatr (Barc). 2020;92:237-8.

32. Piersigilli F, Carkeek K, Hocq C, van Grambezen B, Hubinont C, Chatzis O, et al. COVID-19 in a 26-week preterm neonate. Lancet Child Adolesc Health. 2020;4:476-8.

33. Fang $Y$, Zhang $H$, Xie J, Lin M, Ying L, Pang P. Sensitivity of chest CT for COVID-19: comparison to RT-PCR. Radiology. 2020;296:E115-7.

34. Sethuraman N, Jeremiah SS, Ryo A. Interpreting diagnostic tests for SARS-COV-2. JAMA. 2020;323:2249-51.

35. Wölfel R, Corman VM, Guggemos W, Seilmaier M, Zange S, Müller MA et al. Virological assessment of hospitalized patients with COVID-2019. Nature. 2020;581:465-9. 